\title{
Saccadic eye movements during a concurrent auditory task
}

\author{
FREDERICK V. MALMSTROM \\ Institute of Safety and Systems Management, University of Southern California \\ Los Angeles, California 90089
}

LAWRENCE E. REED
Air Force Human Resources Laboratory, Wright-Patterson Air Force Base, Ohio 45433

and

ROBERT J. WEBER

Oklahoma State University, Stillwater, Oklahoma 74078

\begin{abstract}
Ten adult male subjects participated in an experiment in which they simultaneously visually tracked a jumpwise moving target and identified randomly generated auditory dots and dashes. Results indicated there was both an elimination of discrete saccades and a shortening of eye movement paths. It was also observed that the difficulty of the visual tracking task and the concurrent auditory task showed effects that were not independent of each other. Results could be construed to support both a divided attention and an opponent-process visual processing model.
\end{abstract}

Previous studies by Hess and Polt (1960, 1964), Malmstrom, Randle, Bendix, and Weber (1980), and Malmstrom, Reed, and Randle (Note 1) seemed to implicate sympathetic arousal as a significant effector on coordinated visual processes, including pupillary dilation, an accommodation shift toward the visual far point, and a shortening of the pursuit eye movement paths. All effects are explainable by a sympatheticparasympathetic, or opponent-process, model of visual attention.

The voluntary-involuntary aspect of eye movements complicates such a simple model, however. That saccadic eye movements are largely under voluntary control is self-evident, but reports by Malmstrom and Randle (1976) and Randle (Note 2) indicate that so-called involuntary visual responses, such as accommodation, may be subject to voluntary control under special circumstances.

A previous experiment by Malmstrom et al. (Note 1) explored the effects of a concurrent auditory task on pursuit eye movements, but at the time the effects of a

Requests for reprints should be sent to F. V. Malmstrom, Human Factors Department (MC-0021), Institute of Safety and Systems Management, University of Southern California, Los Angeles, California 90089-0021. Support for this research was provided by the Man-Vehicle Systems Research Division, NASA/Ames Research Center, the U.S. Air Force Human Resources Laboratory, and the U.S. Air Force Rome Air Development Center. However, no endorsement of any agency should necessarily be implied. The authors express their appreciation to Donna L. Miller, Informatics, Inc., and to Bill Schelker and Ed Sanderlin of AFHRL for technical assistance. similar concurrent task on "voluntary" saccadic eye movements were not considered. The effects of a concurrent auditory task on saccadic eye movements cannot be easily predicted by the opponent-process model, as so-called "higher order" eye movements are generated or mediated from no fewer than four separate sites, some cortical and some midbrain (Raphan \& Cohen, 1978). Therefore, we would expect very complex effects of a concurrent task on saccadic eye movements.

Divided attention models, such as those of Kahneman (1973) would predict decrements on the visual performance to be offset by an increase in concurrent task performance. On the other hand, an opponent-process model suggested by Malmstrom et al. (1980) would have predicted a shortening of saccadic eye movement paths. An example of the problems of prediction, an applied study by Ceder (1977) that stated "during stressful [driving] conditions, eye movement distances became shorter while fixation duration becomes longer" could support either model.

\section{METHOD}

\section{Subjects}

The subjects were 10 adult males with at least a high school education. Nine were volunteer active-duty Air Force males, and one was a paid college senior. The only visual requirement was that the subject be able, with uncorrected vision, to visually track a 3-mm moving bright spot through a visual angle of $18 \mathrm{deg}$ from $1.5 \mathrm{~m}$. Each subject participated in a single experimental session that lasted about $1 \mathrm{~h}$.

\section{Stimuli and Apparatus}

All data were measured by a Gulf + Western 1994S oculo- 
meter with the head secured by a hot-wax molded bite bar. All data were recorded from the right eye in digital form and were later replayed and hand scored at a sampling rate of 30 points/ sec.

The subject viewed a $.40 \mathrm{~m}$ vertical $\times .50 \mathrm{~m}$ horizontal cathode-ray tube (CRT) placed $1.5 \mathrm{~m}$ from the eye. The visual angle limits were chosen to approximate the viewing dimensions normally seen by Air Force CRT operators. Hence, on any trial, the subject viewed a 3-mm spot generated on a square-wave time base (either $.5 \mathrm{~Hz}$ or $1.0 \mathrm{~Hz}$ ) moving jumpwise through either a visual angle of (1) $18 \mathrm{deg}$ horizontally or (2) $14 \mathrm{deg}$ vertically.

For the concurrent task, the subject responded with a handheld thumb switch to a series of randomly generated (PDP-11) dots and dashes that he listened to on a headset. A dash was a 300-msec- and a dot a 200 -msec-duration $1,000-\mathrm{Hz}$ tone, not an easy discrimination task. The concurrent task was presented at two difficulties, DF .6 and DF 1.2. For the DF 1.2 , there were approximately 36 tones per the 30 -sec task period $(36 / 30=1.2$, $\mathrm{SD}=2.1)$; for the DF .6, there were approximately 18 tones per the 30 -sec task period $(18 / 30=.6, \mathrm{SD}=.93)$. For both difficulty levels, the ratio was 1.4 dots to 1 dash.

\section{Instructions and Procedure}

After an initial calibration procedure, the subject was given as many practice trials as he desired, either separately tracking the jumpwise target or else identifying dots and dashes with the thumb switch. For the concurrent task, the subject was instructed to press the switch when he heard a dot and to ignore the dashes.

Each experimental trial followed the same general format: The subject was first presented a 10 -sec visual tracking practice period followed by a 10 -sec auditory task dot-dash identification practice period. At this point, the actual experimental trial began. During the initial 30-sec (base) period, the subject was instructed to visually track the jumpwise target only (no audio signals were present). At the end of the base period, the concurrent (task) period with the same visual target was present, but the dot-dash task was added. At the end of the task period, the auditory task ceased, and the target continued its motion for an additional 30 -sec visual tracking (recovery) period. The flow of events for a trial is shown in Figure 1.

\section{Design}

The experimental design for the 10 subjects consisted of random presentations of the two target tracking difficulties $(.5 \mathrm{~Hz}, 1.0 \mathrm{~Hz})$, two target directions (horizontal, vertical), two concurrent auditory task difficulties (DF .6, DF 1.2), and the three time periods (base, task, recovery). All trials were within subjects.

\section{RESULTS AND DISCUSSION}

\section{Visual Tracking Task (Magnitude)}

Figures 2 and 3 are representative raw data of the subjects' visual tracking and concurrent task performance.

Figure 2 shows the results when the subject is presented a simple visual tracking task $(.5 \mathrm{~Hz})$ and the difficult concurrent auditory task (DF 1.2). During this trial, there is little apparent decrease in eye movement magni-

\begin{tabular}{lllll}
\hline $\begin{array}{l}\text { Practice: } \\
\text { Visual Tracking } \\
\text { Only }\end{array}$ & $\begin{array}{l}\text { Practice: } \\
\text { Auditory Concurrent } \\
\text { Task Only }\end{array}$ & $\begin{array}{l}\text { Base Period: } \\
\text { Visual Tracking } \\
\text { Only }\end{array}$ & $\begin{array}{l}\text { Concurrent Task Period: } \\
\text { Visual Tracking and } \\
\text { Auditory Task }\end{array}$ & $\begin{array}{l}\text { Recovery Period: } \\
\text { Auditory Task Ends; } \\
\text { Visual Tracking Continues }\end{array}$ \\
$-20 \mathrm{Sec}$ & $-10 \mathrm{Sec}$ & $\begin{array}{l}0 \mathrm{Sec} \\
\text { Experimental } \\
\text { Trial Begins }\end{array}$ & $+30 \mathrm{Sec}$ & $+60 \mathrm{Sec}$ \\
& & & & $+90 \mathrm{Sec}$ \\
& & & & \\
\hline
\end{tabular}

Figure 1. Flow diagram for sequence of primary visual tracking task and concurrent auditory task.

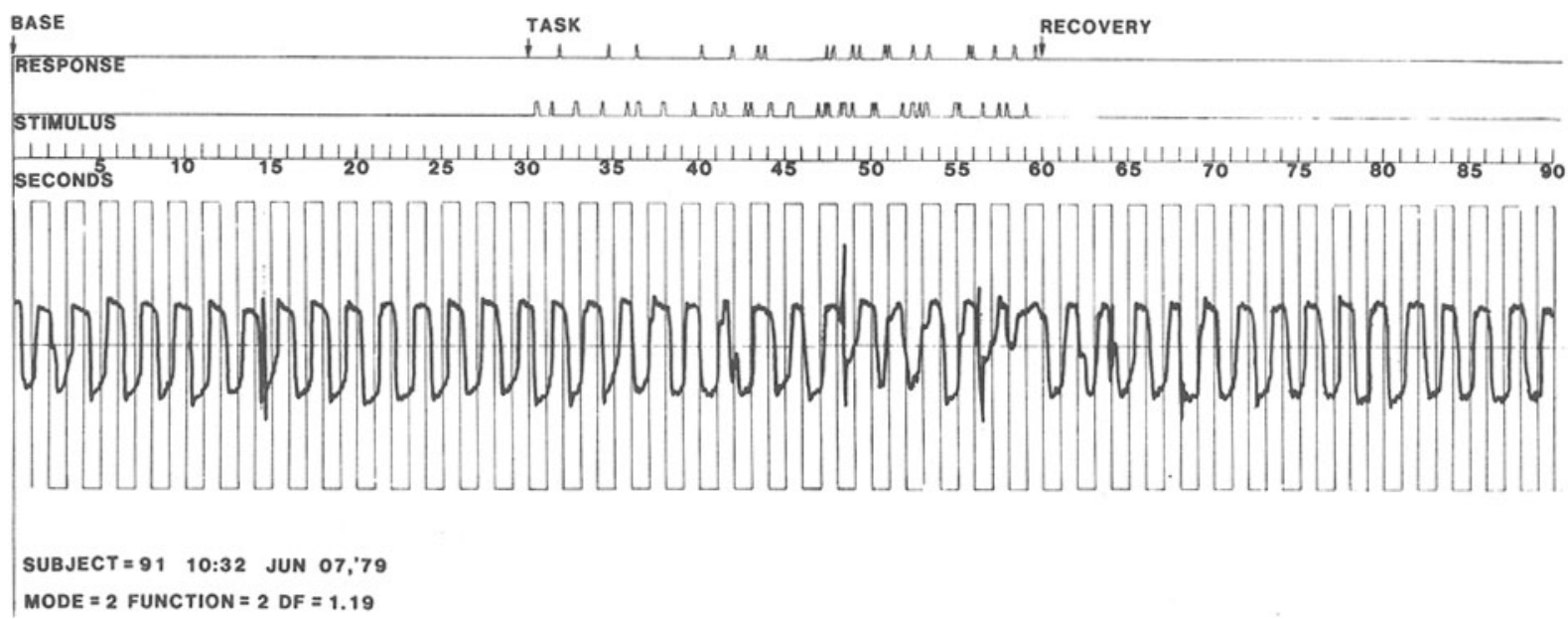

Figure 2. Representative raw data of subject following jumpwise vertical target, frequency $.5 \mathrm{~Hz}$, concurrent task difficulty 1.2. During task, subject misses approximately $4 \%$ of target movements. (Spikes are eye blinks.) 


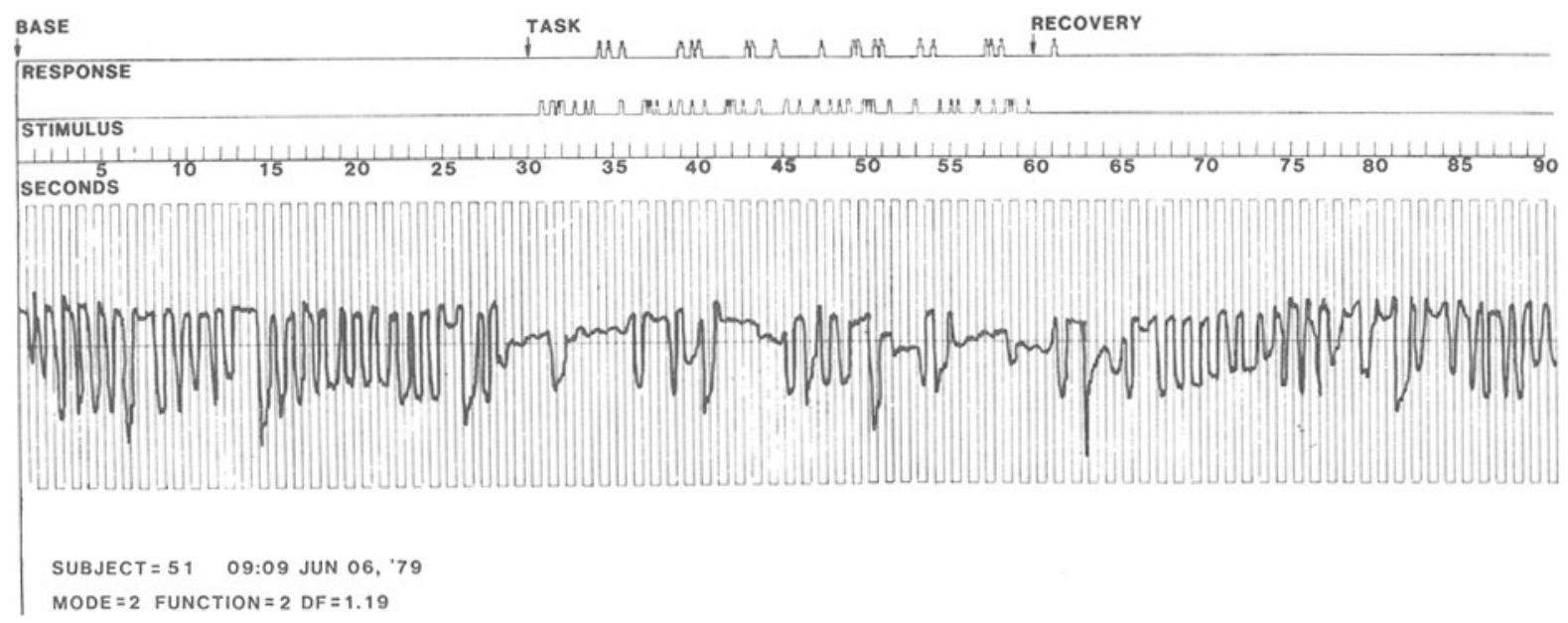

Figure 3. Representative raw data of subject following jumpwise vertical target, frequency $1.0 \mathrm{~Hz}$, concurrent task difficulty 1.2. During task, subject misses approximately $56 \%$ of target movements. (Spikes are eye blinks.)

tude, but there is some tendency for the subject to miss discrete eye movements. Figure 3 indicates that as the tracking difficulty is increased, there is a greater tendency for the subject to miss even more discrete eye movements, accompanied by a decrease in eye movement magnitude. In fact, the overall interference of the concurrent task on discrete saccades was about $65 \%$; shortening of the saccadic magnitude occurred about $35 \%$ of the time. In other words, both kinds of predicted visual interference effects, shortening and elimination of saccades, were evident.

Figure 4 shows the mean saccadic eye movement magnitude plotted as a function of the time periods, task difficulty, and the target frequency.

Target magnitude was defined as the average fixation distance between the right and left, or the high and low,

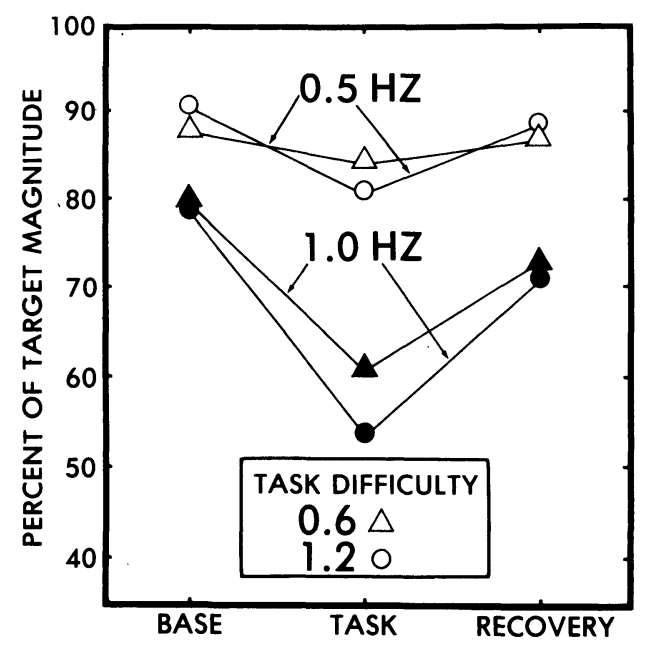

Figure 4. Mean saccadic eye movement magnitude plotted as a percent of target magnitude, concurrent task difficulty, and task periods. excursions of the target jump, averaged over a $30-\mathrm{sec}$ time period. Thus, for a $1.0-\mathrm{Hz}$ time period, each subject's data point consisted of 30 averaged points. For a $.5-\mathrm{Hz}$ time period, each subject's data point consisted of 15 averaged points. Results indicate that there is significant interference of the concurrent auditory task on eye movement magnitude, but that the interference lasts only as long as the concurrent task is present. In addition, there were substantial expected magnitude restriction effects of the target frequency on eye movements. However, and most important, there were joint effects of the concurrent auditory task difficulty and the visual tracking task difficulty (frequency). In other words, the effects of both the visual and the auditory task difficulties are not statistically independent of each other.

Analysis of variance indicated main effects of time periods $[F(2,18)=71.633, p<.001]$ and target frequency $[F(1,9)=109.916, p<.001]$. There were three separate two-way interaction effects: Time Periods by Concurrent Task Difficulty $[\mathrm{F}(2,18)=4.939, \mathrm{p}<.025]$, Time Periods by Target Frequency $[\mathrm{F}(2,18)=20.686$, $\mathrm{p}<.001]$, and Concurrent Task Difficulty by Target Frequency $[F(1,9)=5.906, p<.05]$. In addition, there was a single three-way interaction of Time Periods by Target Direction by Target Frequency $[\mathrm{F}(2,18)=4.861$, $\mathrm{p}<.05]$.

\section{Saccadic Latency}

Latency is defined as the time delay of an appropriate ballistic saccade after the jump of the target to its alternate position. Thus, for a $.5-\mathrm{Hz}$ target, each subject's data point consists of 30 averaged values ( 15 values for each direction). For a $1.0-\mathrm{Hz}$ target, there were twice the number of averaged values. In the event a subject failed to make a discrete saccade during the target jump (about $65 \%$ of the affected responses), that particular value was not computed. 
Results indicated that compared to the base period there was a marked decrease in saccadic latency during the recovery periods. The mean values (in milliseconds) for the base, task, and recovery periods were, respectively, 191, 143, and 154. Analysis of variance for latency yielded a single main effect for time periods $[F(2,18)=6.699, p<.01]$. However, probably owing to huge variances in data, a Newman-Keuls post hoc test failed to show any differences between any pairs of time periods.

\section{Concurrent Auditory Task}

The results of the responses for the concurrent auditory task were tabulated by comparing the subject's hit and false alarm rates. All normalized concurrent task parameters, $\mathrm{d}^{\prime}$ (sensitivity) and $\beta$ (criterion) were computed from the hit and false alarm rates according to the method suggested by Hochhaus (1972). (For further discussion of signal detection theory, the reader is directed to Green and Swets, 1966, and Swets, 1961.)

Analysis of variance for $\mathrm{d}^{\prime}$ (sensitivity) indicated differences between auditory task difficulty levels only $[F(1,9)=8.572, p<.025]$, indicating that there were perceived differences between the two concurrent task difficulties.

\section{GENERAL DISCUSSION}

The results, while showing striking differences in subject performance during the concurrent auditory task, can be argued to show both elements of the opponent-process and the divided attention model. The following effects are cited:

(1) It was expected that the saccadic latency should decrease during the concurrent task. Although decreased performance on the visual tracking task might be said to compensate for increased performance on the auditory task, the results suggest that decreased performance on one aspect of the visual task (magnitude) is compensated for by increased performance on another aspect of the same visual task (latency). Such results might support a divided attention model only for the eye movement aspect, but not the concurrent auditory task aspect. In other words, the implication here is that the addition of a concurrent task acts only as a catalyst to eye movements, forcing the subject to trade off magnitude for speed; the additional capacity for the concurrent task is still unaccounted for.

(2) The overall results of the eye movement magnitudes would seem to implicate both the opponent-process and the divided attention mode. Figure 3, for example, shows an all-ornone response for Seconds 33-36 and a shortened magnitude response for Seconds 4549. In fact, the all-or-none response was indicated in about $65 \%$ of the affected eye movements, leaving the preponderance of the effect to support the divided attention model.
Whatever the implications, the addition of a concurrent auditory task was frequently accompanied by a total elimination of eye movements; on other occasions, the addition of the concurrent auditory task merely served to shorten the saccadic ballistic path. The exact events or causes leading to the two different responses are not yet clear. In any event, both types of magnitude restriction are substantial. Implications of this effect, which parallel the phenomenon of "visual narrowing," are obvious. To wit, the effects of adding the concurrent auditory task sometimes took the target completely out of the subject's foveal cone of vision.

Perhaps, then, results supporting both models should not be surprising, since, as Raphan and Cohen (1978) report, saccadic eye movements can originate in both higher and lower order visual processing centers. There may well be room for both types of effects, and future experiments would do well to consider both the divided attention and the opponent-process models.

\section{REFERENCE NOTES}

1. Malmstrom, F., Reed, L., \& Randle, R. Restriction of pursuit eye movements during a concurrent auditory task. Manuscript submitted for publication, 1982.

2. Randle, R. Volitional control of visual accommodation. Conference Proceeding No. 82 on Adaptation and Acclimatization in Aerospace Medicine. AGARD, NATO, Garmisch-Partenkirchen, Germany, September 14-18, 1970.

\section{REFERENCES}

Ceder, A. Drivers' eye movements as related to attention in simulated traffic conditions. Human Factors, 1977, 19, 571-581.

Green, D. M., \& Swers, J. A. Signal detection theory and psychophysics. New York: Wiley, 1966.

Hess, E., \& Polt, J. Pupil size as related to interest value of visual stimuli. Science, $1960,132,349-350$.

Hess, E., \& PoLt, J. Pupil size in relation to mental activity during simple problem-solving. Science, 1964, 143, 1190-1192.

Hochraus, L. A table for the calculation of $\mathrm{d}^{\prime}$ and $\beta$. Psychological Bulletin, 1972, 77, 375-376.

Kahneman, D. Attention and effort. Englewood Cliffs, N.J: Prentice-Hall, 1973.

Malmstrom, F., \& RANDle, R. Effects of visual imagery on the accommodation response. Perception \& Psychophysics, 1976, $19,450-453$.

Malmstrom, F., Randle, R., Bendix, J., \& Weber, R. The visual accommodation response during concurrent mental activity. Perception \& Psychophysics, 1980, 28, 440-448.

RAPHAN, T., \& Cohen, B. Brainstem mechanisms for rapid and slow eye movements. In E. Knobil, R. Sonnenschein, \& I. Edelman (Eds.), Annual review of physiology (Vol. 40). Palo Alto, Calif: Annual Reviews, Inc., 1978.

SwETs, J. Is there a sensory threshold? Science, 1961, 134, 168177.

(Received for publication December 27, 1982.) 